\title{
THE DISPOSITION OF ACID ADMINISTERED TO SODIUM- DEPLETED SUBJECTS: THE RENAL RESPONSE AND THE ROLE OF THE WHOLE BODY BUFFERS ${ }^{1,2}$
}

\author{
By WILLIAM B. SCHWARTZ, ROBERT L. JENSON, AND ARNOLD S. RELMAN
}

(From the New England Center Hospital and the Department of Medicine, Tufts College

Medical School, and from the Evans Memorial, Massachusetts Memorial Hospitals, and the Department of Medicine, Boston University School of Medicine, Boston, Mass.)

(Submitted for publication October 9, 1953; accepted December 2, 1953)

Previous studies (1-4) on the response of normal human subjects to the administration of mineral acids or acidifying salts have established that: 1) Extracellular bicarbonate concentration and $\mathrm{pH}$ are reduced; and 2) there is a prompt increase in the renal excretion of the administered anion accompanied at first mainly by sodium, potassium, and small amounts of ammonium. Ammonium excretion rises slowly, and after a few days replaces most of the fixed cation in the urine.

Little is known about the mechanisms regulating this renal response, or how it might be modified. Furthermore, although it is evident that the moiety of administered hydrogen not immediately appearing in the urine as ammonium or titratable acid must be accounted for by changes in body buffers, no description has been made of the internal distribution of the retained hydrogen ions. It was pointed out many years ago $(5,6)$ that buffers other than those in whole blood must be important in this process, but there are no quantitative data on the relative importance of red cell, plasma, interstitial fluid, and cellular buffers.

In the present study, acidifying salts were administered to healthy subjects who had previously been depleted of sodium. The purposes of this investigation were $: 1$ ) To attempt a quantitative description of the internal distribution of the retained hydrogen ion and thereby clarify the relative importance of the various body buffers in the extrarenal adjustments to acid loading; and 2) to

1 This study was supported in part by grants from the National Heart Institute of the National Institutes of Health, U.S.P.H.S., the Greater Boston Chapter of the Massachusetts Heart Association and from the Research and Development Bcard, Surgeon General's Office, Department of the Army.

2 Presented in abstract at the 45th annual meeting of the American Society for Clinical Investigation, May, 1953. determine how sodium depletion might modify the nature of the cation diuresis, and particularly how it might change the renal ammonium response.

\section{METंHODS}

Five balance studies were carried out on five healthy male medical students. Sodium depletion was produced over a period of four to five days by a low-sodium diet (10 to $20 \mathrm{mEq}$. per day) and a total of one to three injections of a mercurial diuretic. During this period the subjects lost an average of $2.4 \mathrm{Kg}$. (range: 1.7 to 2.7 $\mathrm{Kg}$.). The low-sodium diet was continued and the balance study was begun with a control period of at least four days, during which time serum concentrations and urinary excretion of electrolytes were approximately constant. Following this, three subjects were given ammonium chloride (721 to $1028 \mathrm{mEq}$. of chloride) and two subjects ammonium sulfate (400 and $504 \mathrm{mEq}$. of sulfate) in divided oral doses over a two to three-day period. In each instance a post-treatment period of one or more days was obtained. The subjects were allowed to continue their usual activities during the period of study but were instructed to avoid exertion.

Urine inorganic sulfate was determined gravimetrically as barium sulfate (7). The other analytic procedures, as well as the details of the balance technique, have been described in a previous paper from this laboratory (8).

Hydrogen ion balance was calculated as the difference between hydrogen (ammonium) intake and the increment of urine ammonium and titratable acid above the control period. The use of the control acid excretion as a baseline appeared justified in view of the fact that nitrogen balance did not change and organic acid excretion was essentially constant (see below). A small increase in phosphate excretion during the acidification period was disregarded because, although it is not clear whether phosphate is released from bone or cells in acid or alkaline form, the quantity of titratable acid or alkali so liberated is negligible. Possible changes in non-protein respiratory quotient were disregarded because of the fact that excretion of carbon dioxide is accomplished without any net gain or loss of hydrogen.

The distribution of retained hydrogen ion in the buffers of the blood was estimated from changes in plasma 
bicarbonate and $\mathrm{pH}$ in the fashion described by Singer and Hastings (9). For these calculations blood volume was taken to be $80 \mathrm{cc}$. per kilogram of body weight and, because of the small changes in hemoglobin and hematocrit, red blood cell volume and plasma volume were considered to be constant. Initial extracellular fluid volume was arbitrarily taken to be 20 per cent of body weight. Changes in this volume were estimated from changes in the chloride space. The buffer contribution of interstitial fluid was calculated from the observed recuction in plasma bicarbonate with the use of a Donnan factor of 1.11. Intracellular transfer of hydrogen was calculated from the difference between total retained hydrogen and the decrease in buffer equivalence of whole blood and interstitial fluid. Internal exchanges cf solium were calculated from the changes in chloride space. Cell balances of potassium were considered approximately equivalent to the net external potassium balance, because serum potassium concentrations did not change significantly and the cumulative nitrogen balances were cssentially unaffected. Calculations of hydrogen balance were made only for the three ammonium chloricle cxpcriments, in which the negligible output of the loading anion in the stool indicated complete absorption of the ac'ministered salt. In these three studies the stools were analyzed for sodium, potassium, and nitrogen as well as for chloride.

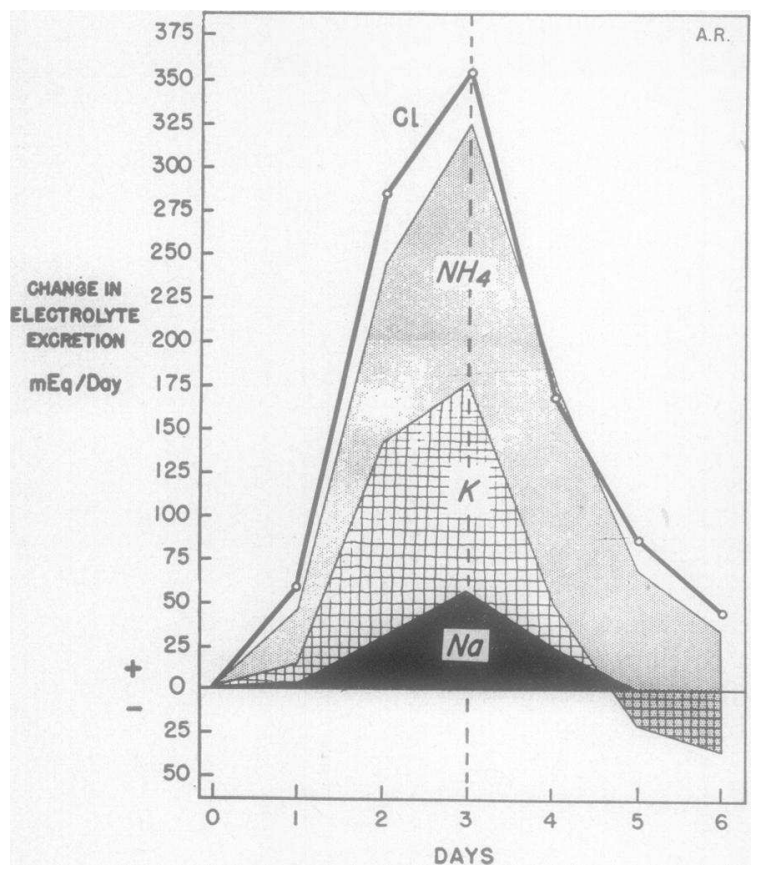

Fig. 1. Changes in the Daily Excretion of the Major Urinary Cations (Above or Below the Average Control Rates), and the Daily Increments in Excretion of the Loading Anion (See Text for FurTHER EXPLANATION)

Dotted line indicates end of treatment period.

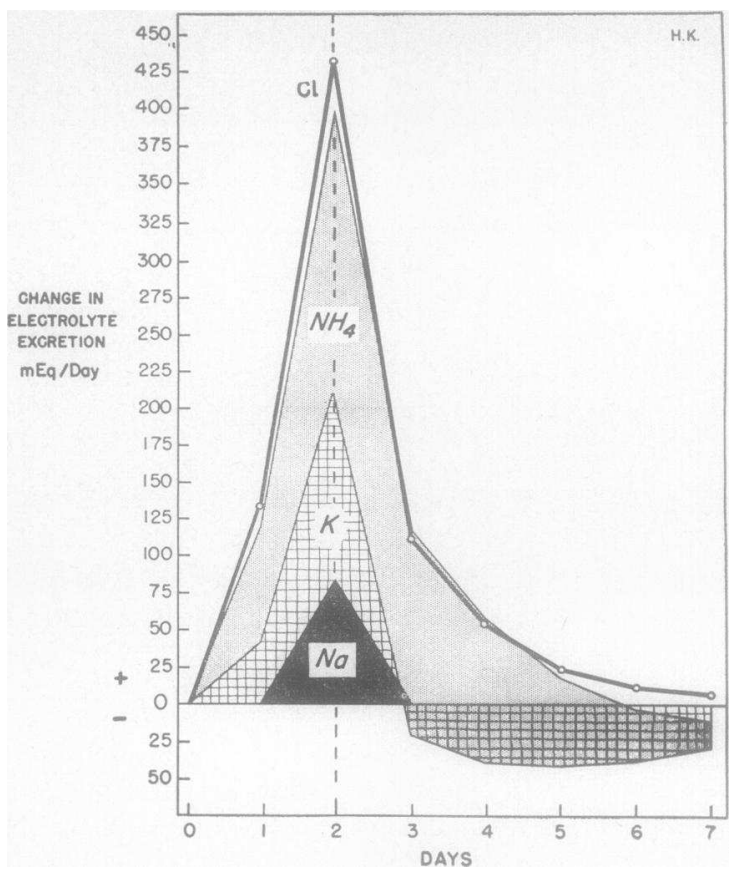

Fig. 2. Changes in the Daily Excretion of the Major Urinary Cations (Above or Below the Average Control Rates), and the Daily Increments in Excretion of the ioaning Anion (See Text for Further Explanation )

Dotted line indicates end of treatment period.

\section{RESULTS}

\section{General Effects}

The three subjects given ammonium chloride tolerated this salt without untoward effects other than slight nausea and abdominal cramping. Ammonium sulfate produced mild diarrhea in both subjects. In no subject did any signs or symptoms of potassium deficiency appear. Serial electrocardiograms showed no abnormalities (10).

\section{Changes in Urine Composition and Balance of Electrolytes}

Tables I-II and Figures 1-5 present the data on the five subjects. The figures show increments in the excretion of the major cations above their average control rates and the increments in the excretion of the loading anion. The cations are plotted additively so that the uppermost line represents the total cation increase. For simplicity in presentation, titratable acid is not shown although it regularly increased slightly (Tables I and II). 


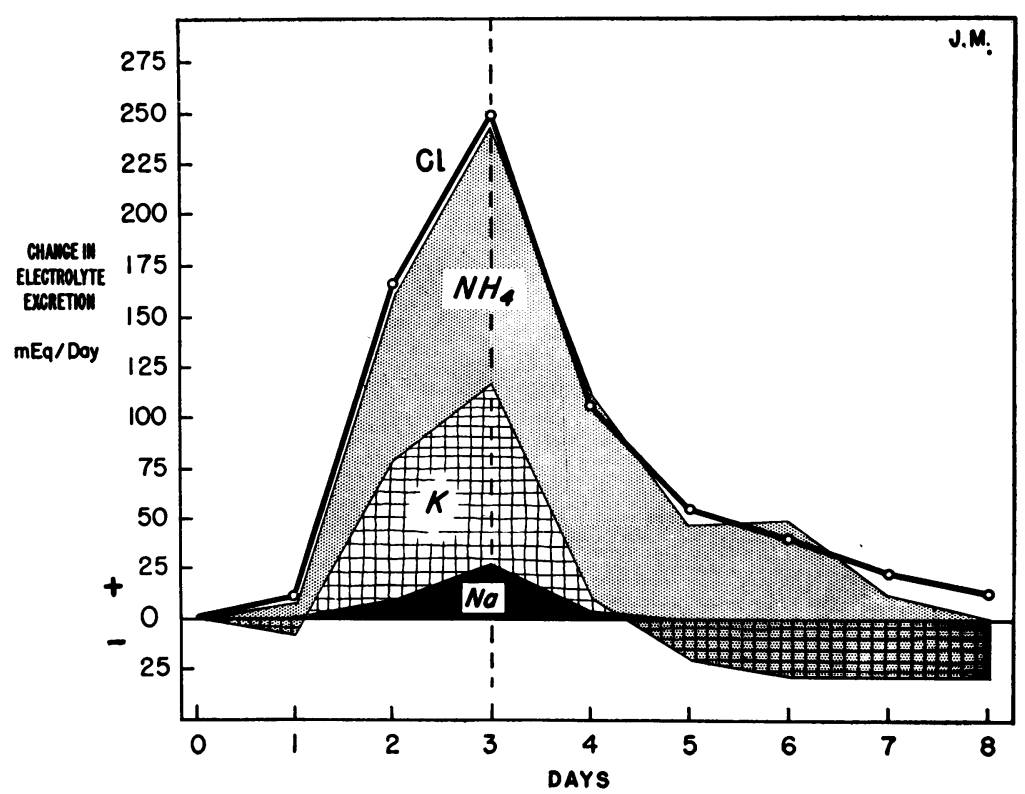

Fig. 3. Changes in the Daily Excretion of the Major Urinary Cations (Above or Below the Average Control Rates), and the Daily Incriments in Excretion of the Londing Anion (See Text for Further Explanation)

Dotted line indicates end of treatment period.

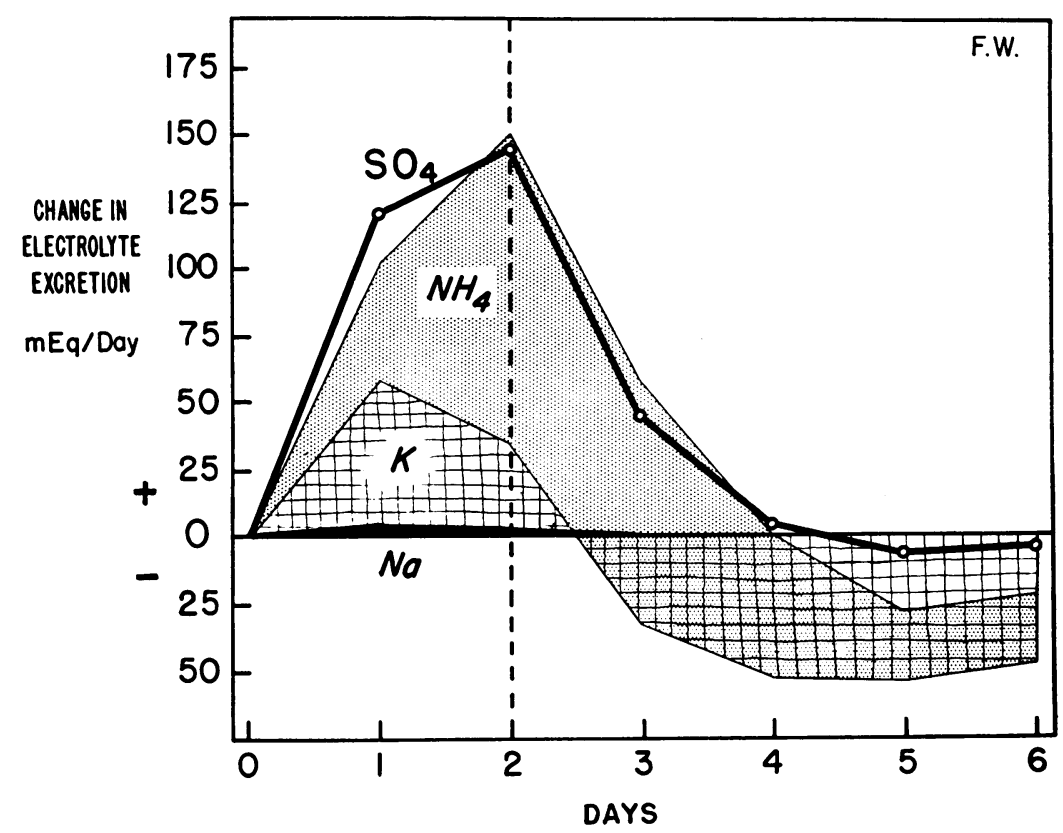

Fig. 4. Changes in the Daily Excretion of the Major Urinary Cations (Above or Below the Average Control Rates), and the Daily Increments in Excretion of the Loading Anion (See Text for Further EXPLANATION) 


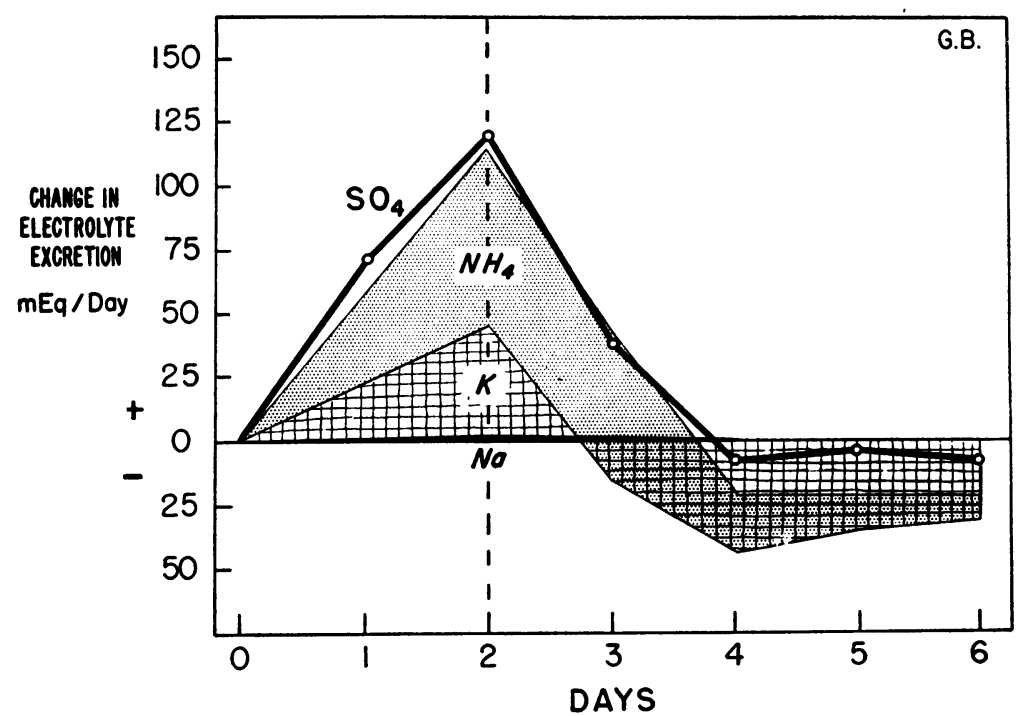

Fig. 5. Changes in the Daily Excretion of the Major Urinary Cations (Above or Below the Average Control Rates), and the Daily Increments in Excretion of the Loading Anion (See Text for Further Explanation)

Dotted line indicates end of treatment period.

Calcium and magnesium, two relatively small components of fixed cation output in the urine, were not measured. It should be noted that in the postacidification period, when there were positive balances of potassium, the decrements from the control period are plotted downward from the zero line and ammonium is plotted upward from the most negative point.

\section{A. Acidification period}

As shown in the figures and tables the main features of the acidification period were the following :

1. The algebraic sum of the increments in ammonium, sodium and potassium always very closely approximated the increments in the loading anion.

TABLE I

Experimental data

A. $\mathbf{R}$.

\begin{tabular}{|c|c|c|c|c|c|c|c|c|c|c|c|c|}
\hline \multirow[b]{2}{*}{ Day } & \multirow[b]{2}{*}{ Medications } & \multirow{2}{*}{$\begin{array}{c}\text { Body } \\
\text { weight }\end{array}$} & \multicolumn{5}{|c|}{ Intake } & \multicolumn{5}{|c|}{ Vrine } \\
\hline & & & $\mathrm{H}_{2} \mathrm{P}$ & $\mathrm{Na}$ & $\mathrm{K}$ & $\mathrm{Cl}$ & $\mathrm{N}$ & Vol. & $\mathrm{Na}$ & $\mathrm{K}$ & $\mathrm{Cl}$ & $P$ \\
\hline & & $K g$. & $c c$. & $m E q$. & $m E q$. & $m E q$. & $G m$ & $c r$. & $\begin{array}{c}m E q . .^{\prime} \\
d z y\end{array}$ & $\begin{array}{c}\text { mEq.' } \\
\text { day }\end{array}$ & $\underset{\text { day }}{m E q . /}$ & $\begin{array}{l}m M / \\
d \mathfrak{t} y\end{array}$ \\
\hline 1 & & 89.55 & 2800 & 15 & 105 & 29 & 18.8 & 1940 & 11 & 92 & 18 & 33 \\
\hline 2 & & 89.19 & 2800 & 15 & 105 & 29 & 18.8 & 2310 & 17 & 95 & 15 & 29 \\
\hline 3 & & 89.06 & 2800 & 15 & 105 & 29 & 18.8 & 2925 & 18 & 91 & 17 & 30 \\
\hline 4 & & 88.80 & 2800 & 15 & 105 & 29 & 18.8 & 2200 & 0 & 71 & 7 & 29 \\
\hline 5 & $\begin{array}{c}\mathrm{NH}_{4} \mathrm{Cl} \\
280 \mathrm{mEq} .^{*}\end{array}$ & 89.42 & 2800 & 15 & 105 & 309 & 22.7 & 2305 & 2 & 84 & 65 & 30 \\
\hline 6 & $\begin{array}{c}\mathrm{NH}_{4} \mathrm{Cl} \\
374 \mathrm{mEq} .\end{array}$ & 88.95 & 2800 & 15 & 105 & 403 & 24.0 & 2905 & 31 & 182 & 292 & 42 \\
\hline 7 & $\begin{array}{c}\mathrm{NH}_{4} \mathrm{Cl} \\
374 \mathrm{mEq} .\end{array}$ & 88.60 & 2800 & 15 & 105 & 403 & 24.0 & 3290 & 58 & 189 & 361 & 47 \\
\hline 8 & & 87.60 & 2800 & 15 & 105 & 29 & 18.8 & 2860 & 26 & 96 & 176 & 38 \\
\hline 9 & & 87.35 & 2800 & 15 & 105 & 29 & 18.8 & 2160 & 4 & 47 & 94 & 22 \\
\hline $\begin{array}{l}10 \\
11\end{array}$ & & 87.15 & $2800_{z}$ & 15 & 105 & 29 & 18.8 & 2060 & 1 & 35 & 53 & 21 \\
\hline
\end{tabular}

\footnotetext{
* Chloride and nitrogen administered as ammonium chloride included in total intake value.
} 
TABLE I-Continued

Experimental data

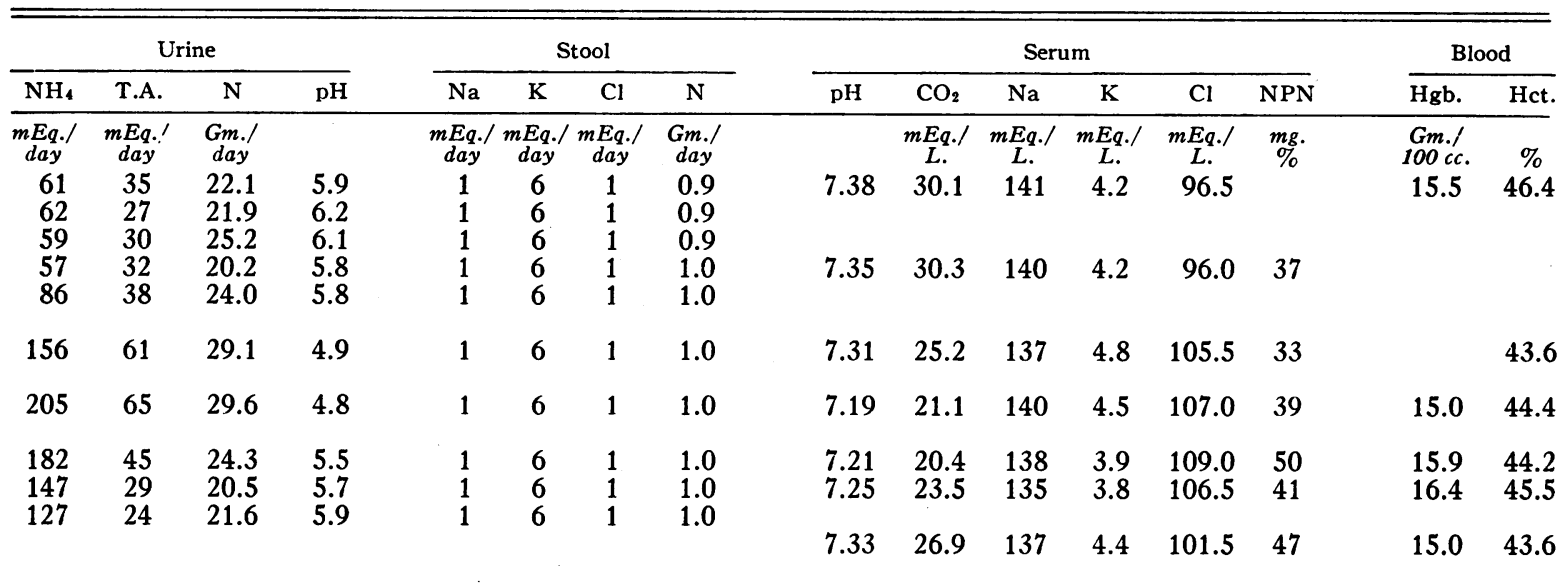

2. During the first day in the subjects given ammonium chloride, chloride excretion was very low compared to the administered load. Sulfate excretion, on the other hand, increased promptly in subjects given ammonium sulfate.

3. There was a prompt increase in the ammonium excretion of all subjects. This increase was equal to one-third to one-half of the total anion increment for the first day. The largest ammonium increment on the first day was $76 \mathrm{mEq}$. $(\mathrm{H}$. $\mathrm{K}$.). The absolute increase in urinary ammonium during the first two days was directly related to the magnitude of the anion diuresis (Figure 6), but was not well correlated with the urine $\mathrm{pH}$. Except for patient $\mathrm{H}$. K., who had at once the largest initial anion excretion and urinary ammonium response as well as the greatest depression of extracellular bicarbonate and $\mathrm{pH}$, there was no relationship between initial ammonium excretion and plasma $\mathrm{pH}$ or bicarbonate. For example, the ammonium excretion of subjects G. B. and F. W. increased $35 \mathrm{mEq}$. and $42 \mathrm{mEq}$., respectively, in one day (Figure 4,5 ), with a reduction of only 1 to 2 $\mathrm{mEq}$. per liter in plasma carbon dioxide content and no significant change in blood $\mathrm{pH}$ (Table II). By contrast, subject A. R. (Table I), who had a

TABLE II

Experimental data

G. B.

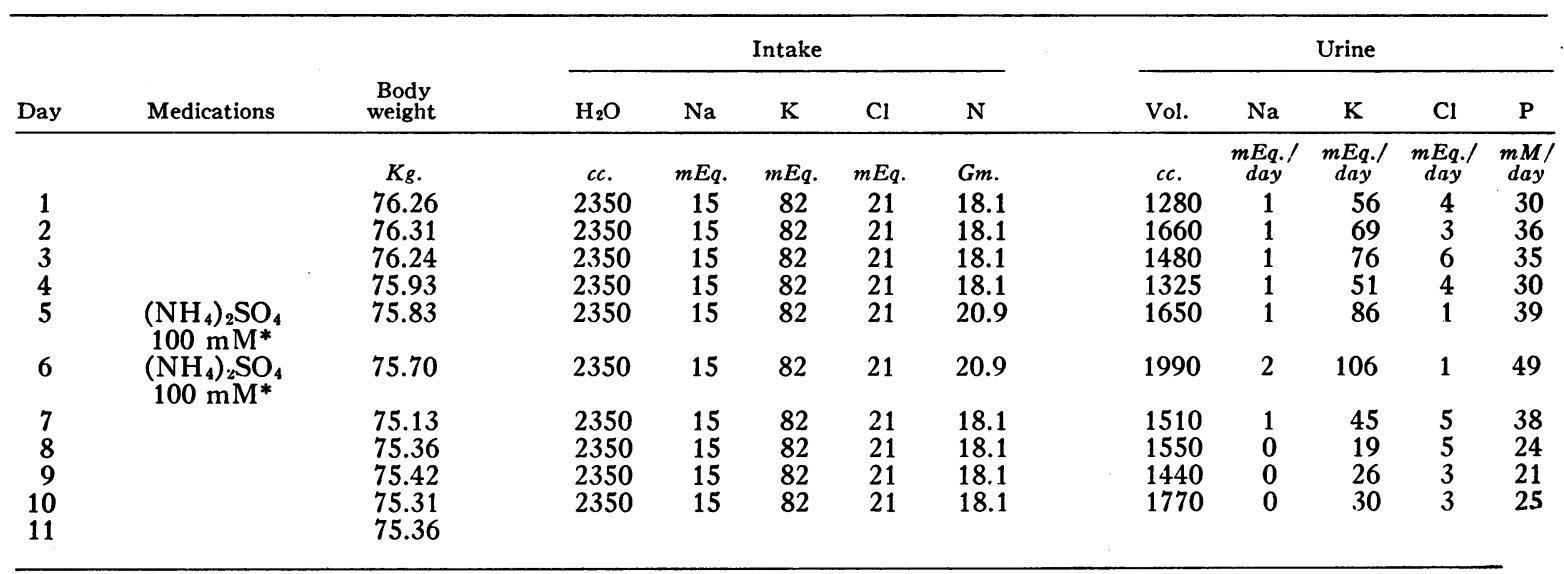

* Nitrogen administered as ammonium sulfate included in total intake value. 
TABLE II-Continued

Experimental data

\begin{tabular}{|c|c|c|c|c|c|c|c|c|c|c|c|c|}
\hline \multicolumn{5}{|c|}{ Urine } & \multicolumn{6}{|c|}{ Serum } & \multicolumn{2}{|c|}{ Blood } \\
\hline $\mathrm{NH}_{4}$ & T.A. & $\begin{array}{l}\text { Org. } \\
\text { acids }\end{array}$ & $\mathrm{N}$ & $\mathrm{pH}$ & $\mathrm{pH}$ & $\mathrm{CO}_{2}$ & $\mathrm{Na}$ & $\mathrm{K}$ & $\mathrm{Cl}$ & NPN & Hgb. & Hct. \\
\hline$\overline{m E q . /} \begin{array}{c}m E q \\
d a y\end{array}$ & $\underset{d a y}{m E q . /}$ & $\begin{array}{c}m E q . / \\
\text { day }\end{array}$ & $\begin{array}{c}G m . / \\
\text { day }\end{array}$ & & & $\begin{array}{c}m E q . / \\
L .\end{array}$ & $\begin{array}{c}m E q . / \\
L .\end{array}$ & $\begin{array}{c}m E q . / \\
L .\end{array}$ & $\begin{array}{c}m E q . / \\
L .\end{array}$ & $\underset{\%}{m g .}$ & $\begin{array}{c}\text { Gm.' } \\
100 \mathrm{cc} \text {. }\end{array}$ & $\%$ \\
\hline $\begin{array}{l}74 \\
75\end{array}$ & $\begin{array}{l}38 \\
39\end{array}$ & $\begin{array}{l}65 \\
68\end{array}$ & $\begin{array}{l}18.8 \\
18.9\end{array}$ & $\begin{array}{l}5.8 \\
5.9\end{array}$ & 7.34 & 28.8 & 140 & 4.5 & 96 & 32 & 15.1 & 42.7 \\
\hline 66 & 39 & 70 & 18.9 & 6.0 & & & & & & & & \\
\hline 67 & 34 & 63 & 17.6 & 5.8 & 7.33 & 32.5 & 140 & 4.1 & 96 & & 14.3 & 42.6 \\
\hline 101 & 49 & 75 & 19.4 & 5.5 & 7.32 & 31.3 & 140 & 4.4 & 98 & & 14.0 & 41.1 \\
\hline 134 & 56 & 82 & 19.3 & 5.3 & 7.32 & 30.4 & 140 & 4.0 & 96 & 38 & & \\
\hline \multirow{4}{*}{$\begin{array}{r}124 \\
89 \\
82 \\
73\end{array}$} & 40 & 70 & 17.2 & 5.8 & 7.30 & 29.0 & 140 & 4.1 & 97 & & 14.9 & 42.3 \\
\hline & 23 & 72 & 17.5 & 6.1 & 7.32 & 29.5 & 140 & 3.8 & 97 & 32 & 14.3 & 40.1 \\
\hline & 24 & $\begin{array}{l}68 \\
75\end{array}$ & $\begin{array}{l}17.6 \\
166\end{array}$ & 6.0 & & & & & & & & \\
\hline & & & & & & & 140 & 4.3 & & 39 & & \\
\hline
\end{tabular}

significant drop in serum $\mathrm{pH}$ and a decrease of 5 $\mathrm{mEq}$. in carbon dioxide content, increased ammonium excretion on the first day by only $29 \mathrm{mEq}$. (Figure 1).

4. In all experiments potassium was the major fixed cation in the urine during the acidification period. In the sulfate experiments there was essentially no loss of sodium, and in the chloride experiments the excretion of sodium lagged far behind that of potassium. The cumulative losses of potassium during the treatment period were 66 to $242 \mathrm{mEq}$., while sodium losses were only 1 to 91 $\mathrm{mEq}$. Despite the size of the potassium deficits there were no significant or consistent changes in serum potassium.

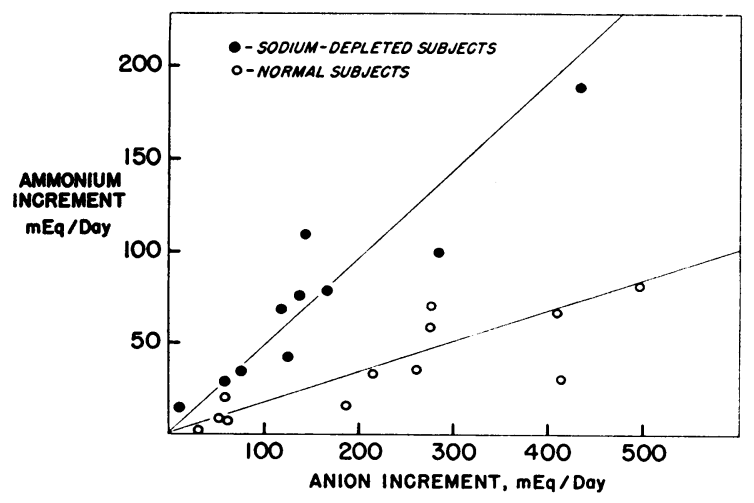

Fig. 6. Relation between Increment in Daily Ammonium Excretion Above Average Control. Level and the Increment in Loading Anion, for the First Two Days of Acid Loading

The data on non-depleted subjects were obtained from Reference Nos. 1, 3, and 4.
Figure 7 illustrates the relationship between the daily increment in anion excretion and the increase in sodium excretion for all twelve acidification days of the five experiments. The data demonstrate that with daily anion increments of less than approximately $125 \mathrm{mEq}$. there was no significant increase in sodium excretion. At anion increments in excess of this amount there appeared to be a roughly linear relationship between anion increment and sodium increment. The slope of the line indicates that with each $100 \mathrm{mEq}$. of anion increment above $125 \mathrm{mEq}$. there is a sodium loss of roughly $25 \mathrm{mEq}$.

5. Organic acid excretion did not change in H. K., J. M., and F. W., but there was a small increase in G. B. The failure of ammonium chloride to affect excretion of organic acids has been noted previously (4).

Phosphate excretion transiently increased 10 to $20 \mathrm{mM}$ per day in all subjects.

\section{B. Post-acidification period}

The post-acidification period in each subject was characterized by a rapid decline in anion excretion as the administered load was removed from the body and an even more prompt reduction in sodium and potassium excretion. In each case a positive balance of potassium developed by the first or second post-acidification day. The cumulative retention of potassium at the end of both ammonium sulfate studies was in excess of the total loss during the acidification period (Figures 4, 5), but unfortunately none of the balances were continued 


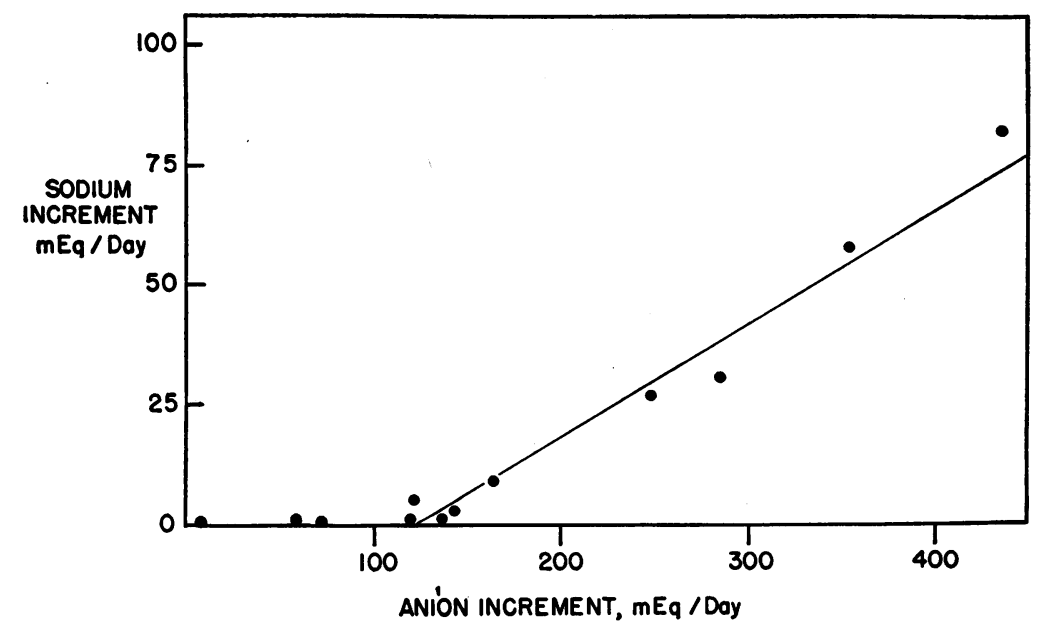

Fig. 7. Relation Between Increment in Daily Sodium Excretion and the Increment in Loading Anion for All Twelve Days of Acidification

(Three subjects given acid loads for two days, two subjects for three days.)

long enough to allow subjects to return to a state of electrolyte equilibrium. Ammonium not only balanced the diminishing increment of anion in the urine but also replaced most of the retained potassium (Figures 1-5) with the result that the excretion of ammonium diminished more slowly than that of any other electrolyte. During several of the last few days of the studies on H. K., J. M., and F. W. (Figures 2, 3, 4) ammonium excretion remained significantly above control levels despite the virtual or complete disappearance of extra anion from the urine.

\section{Distribution of Hydrogen Ion and Internal Shifts of Electrolytes}

Table III lists the net retention of hydrogen ion for each of the three subjects given ammonium chloride, as well as the calculated change in chloride space (initially estimated at 20 per cent of body weight) and the cellular exchanges of hydrogen, sodium, and potassium. In addition, there is listed for comparison the calculated cellular uptake of hydrogen based on an assumed initial extracellular space of 30 per cent body weight. The subjects given ammonium sulfate were not included because they developed diarrhea which obviously would prevent accurate estimation of hydrogen balance.

In all three subjects large quantities of hydrogen appeared to enter cells, while potassium simultaneously was transferred out of cells. In the two subjects retaining the largest hydrogen loads $(\mathrm{J}$. M. and A. R.) there was also a transfer of sodium from cells and chloride space expanded slightly;

TABLE III

Calculated cellular exchanges of hydrogen, sodium and potassium, and calculated change in E.C.F.

\begin{tabular}{|c|c|c|c|c|c|c|}
\hline \multirow[b]{3}{*}{ Subject } & \multirow[b]{3}{*}{ Retained $\mathrm{H}^{+}$} & \multicolumn{4}{|c|}{ Initial E.C.F. estimated as $20 \%$ B.W. } & $\begin{array}{l}\text { Initial E.C.F. } \\
\text { estimated as } \\
\text { 30\% B.W. }\end{array}$ \\
\hline & & & \multicolumn{4}{|c|}{ Changes in intracellular electrolyte content } \\
\hline & & $\Delta$ E.C.F. & $\Delta \mathrm{H}^{+}$ & $\Delta \mathrm{K}^{+*}$ & $\Delta \mathrm{Na}^{+}$ & $\Delta \mathrm{H}^{+}$ \\
\hline $\begin{array}{l}\text { H. K. } \\
\text { J. M. } \\
\text { A. R. } \\
\text { Føllingt }\end{array}$ & $\begin{array}{r}m E q . \\
430 \\
553 \\
684 \\
868\end{array}$ & $\begin{array}{c}L . \\
-0.4 \\
+1.4 \\
+1.1 \\
+0.9\end{array}$ & $\begin{array}{l}m E q . \\
+201 \\
+258 \\
+475 \\
+625\end{array}$ & $\begin{array}{l}m E q . \\
-169 \\
-150 \\
-242 \\
-281\end{array}$ & $\begin{array}{l}m E q . \\
-\quad 2 \\
-227 \\
-172 \\
-356\end{array}$ & $\begin{array}{l}m E q . \\
+96 \\
+104 \\
+353 \\
+529\end{array}$ \\
\hline
\end{tabular}

* Estimated as cumulative loss of potassium.

$\dagger$ Calculated from data in Reference No. 3. 


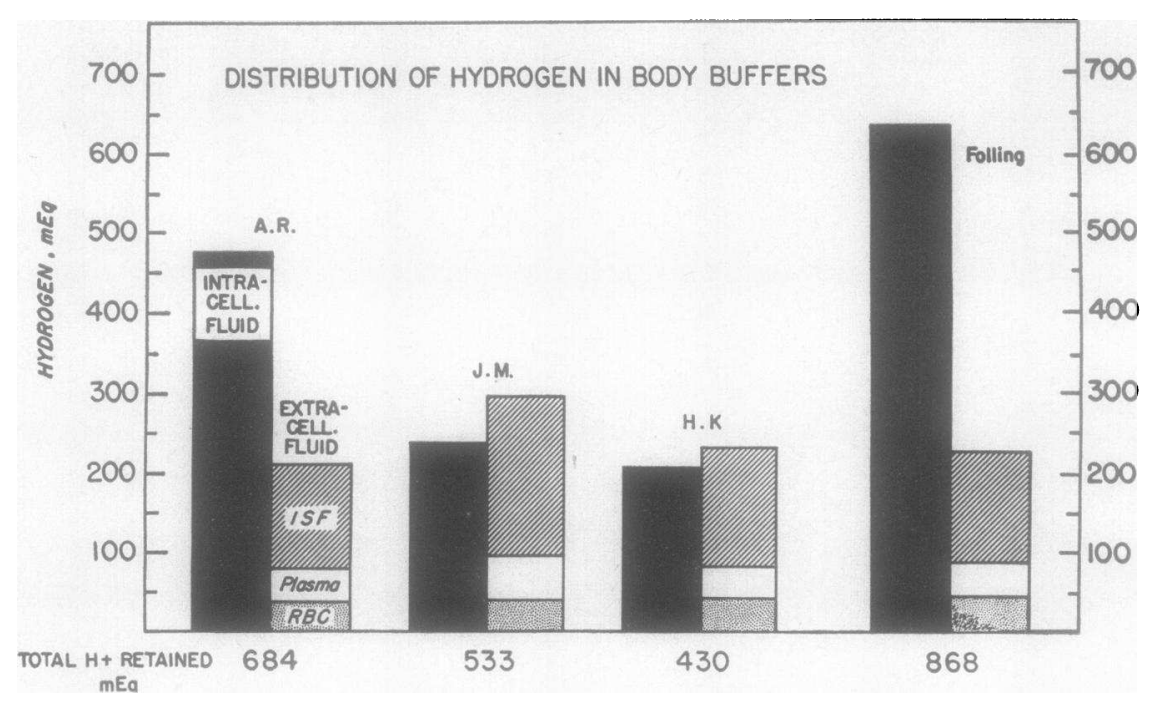

Fig. 8. The Calculated Distribution of Retained Hydrogen among Body Buffers in Thiree Sodium-Depleted Subjects and in Follimg (3)

in $\mathrm{H}$. K. there was an insignificant contraction of the space and no significant sodium transfer.

The distribution of hydrogen among the body buffers is shown in Figure 8. An illustrative calculation for subject A. R. is shown in more detail in Table IV. As is evident from Figure 8 and from the data in Tables III and IV, only a small portion of the retained acid (12 per cent to 18 per cent) was buffered by the blood, with the red cells and the plasma accounting for approximately equal amounts of hydrogen. Interstitial fluid buffered a much larger share (19 per cent to 44 per cent) of the retained acid. The greatest part of the buf-

TABLE IV

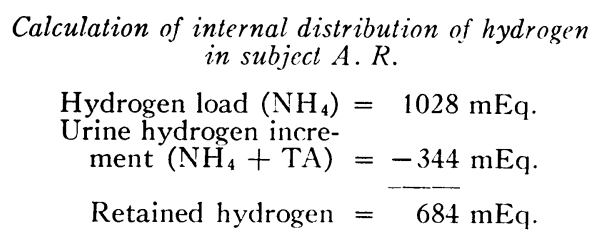

\begin{tabular}{|c|c|}
\hline $\mathrm{RBC}<\mathrm{HCO}_{3}$ & $\begin{array}{l}23 \\
16\end{array}$ \\
\hline Plasma $<\begin{array}{l}\mathrm{HCO}_{3} \\
\text { Protein }\end{array}$ & $\begin{array}{r}38 \\
4\end{array}$ \\
\hline Interstitial fluid & 128 \\
\hline Extracellular buffers & 209 \\
\hline $\begin{array}{l}\text { Retained hydrogen } \\
\text { Extracell. buffers }\end{array}$ & $\begin{array}{r}684 \\
-209\end{array}$ \\
\hline Intracell. buffers & 475 \\
\hline
\end{tabular}

Changes in equivalence of body buffers fering was done by the intracellular fluid which took up 43 per cent to 69 per cent of the retained hydrogen.

\section{DISCUSSION}

The observations reported here appear to confirm the original suggestion of Van Slyke and Cullen (5) and Haldane (6) that a large part of the neutralization of administered acids is done by tissue buffers. These earlier workers based their hypothesis on the observation that administration of acidifying substances resulted in the buffering of much more acid than could be accounted for by the decrease in blood bicarbonate, but no attempt was made to quantitate the distribution of hydrogen among body compartments or to study the exchanges of hydrogen with tissue cations. Further support for the concept of tissue buffering is afforded by recalculation of Følling's data (3) on ammonium chloride acidosis. The analysis of his experiment (the only previously published study which provides data complete enough to make these calculations) is summarized in the right hand columns of Figure 8 and in Table III. It can be seen that the buffers of the extracellular fluid (including blood buffers) neutralized only one-quarter of the retained hydrogen, indicating once again that most of these ions must have entered intracellular ${ }^{3}$ fluid.

\footnotetext{
3 The term "intracellular" is used broadly in this discussion to refer to all non-extracellular areas in which
} 
Calculation of the distribution of retained hydrogen is necessarily based on certain assumptions about the volume of the extracellular fluid compartments, but the qualitative validity of the above conclusions does not depend upon the accuracy of such assumptions. In the present analysis we have taken the initial extracellular volume to be 20 per cent of body weight. Assumption of any volume smaller than this only serves to increase the magnitude of the apparent intracellular buffering. On the other hand, an assumed initial volume of even 30 per cent would still define large intracellular hydrogen ion shifts in our three subjects and in Følling as well (Table III).

The data in Figure 8 indicate that the buffers in blood contribute only a very small amount ( 12 per cent to 18 per cent) to the total body buffering of retained hydrogen. It is also evident that although the total "buffer base" value for red blood cells is greater than that of plasma (9) each neutralized an approximately equal quantity of hydrogen. These results indicate that any consideration of clinical acid-base disturbances devoted exclusively to the red cells and plasma (9, 12) fails to take into account the quantitatively more significant changes in interstitial and intracellular fluid. It is, of course, obvious that hemoglobin is of critical importance to the organism in the buffering of carbonic acid during $\mathrm{CO}_{2}$ transport to the lungs.

Once it is appreciated that large quantities of administered hydrogen ions regularly enter cells, the full significance of the large negative balances of potassium becomes apparent. Since serum potassium concentration did not decline, nitrogen balance did not change significantly, and organic acid excretion increased only slightly, the increment in potassium excretion must chiefly represent intracellular cation exchanged for hydrogen ion. Cellular uptake of hydrogen in exchange for potassium occurs when tissue is depleted of potassium by administration of DOCA and low potassium diets $(13,14)$, and the present observations demonstrate that a similar exchange may occur in reverse sequence, as a result of primary cellular penetration of hydrogen. In two of the pres-

hydrogen buffering might occur. This probably includes not only muscle and other soft tissues, but also bone, which has been demonstrated to have a large labile store of sodium and potassium (11). ent cases and in Følling's experiment, the estimated loss of intracellular potassium was considerably less than the calculated uptake of hydrogen (Table III), indicating that some other cellular cation, probably sodium, was also exchanged. Calculations of the cellular exchanges of sodium based on the chloride space support this concept by revealing negative cell balances large enough roughly to account for the discrepancy between hydrogen and potassium (Table III). Similar exchanges of cellular cation have been observed by Swan and Pitts (15) who reported that infusion of strong acid into nephrectomized dogs mobilized large quantities of bone and tissue sodium and smaller amounts of potassium. On the other hand, if one does not wish to assume a strictly extracellular position for chloride, the observed discrepancy between cellular loss of potassium and uptake of hydrogen in the present study would have to be explained by simultaneous transfer of hydrogen and chloride to the intracellular space.

The extreme reluctance of the sodium-depleted organism to excrete sodium despite the rapid excretion of loading anion is demonstrated by examination of the data in Figure 7. These differ markedly from previously published observations on non-depleted subjects $(3,4)$, in whom the increment in sodium excretion constituted more than half of the total initial cation diuresis. The data in Figure 7 imply that acidifying salts (particularly in the doses of 100 to $150 \mathrm{mEq}$. per day ordinarily employed) are probably of very limited value as a diuretic in the presence of marked renal sodium retention. In this circumstance one might expect acidifying salts to produce a diuresis mainly of intracellular rather than extracellular cation. Support for this concept is afforded by the studies of other investigators (16) who observed large losses of potassium and only little diuresis of sodium in patients with severe congestive failure given ammonium chloride.

The prolonged excretion of ammonium in excess of the loading anion, which continues in the postacidification period, probably represents release of intracellular hydrogen ion. Hydrogen ion released from cells in exchange for extracellular sodium (subjects J. M. and A. R., Table III) would be excreted as ammonium with the loading anion, but hydrogen exchanged for potassium would have to appear in the urine as an incre- 
ment in ammonium in excess of the increment of loading anion. That such a hydrogen-potassium exchange did occur is strongly suggested by the fact that cellular uptake of potassium, as measured by the positive balance during the post-acidification period, was very closely approximated by the increment of urinary ammonium in excess of the loading anion (Figures 1-5). Since extracellular potassium concentration showed little or no change (Tables I and II) the immediate stimulus for the striking renal retention of potassium in the post-acidification period must have been either some humoral or neural signal or a change in the composition of renal tubular cells.

What controls the rate of renal ammonium production? These data are in agreement with the results of other studies $(4,8,17-19)$ in that they fail to demonstrate any quantitative relation between extracellular acidosis or urine $\mathrm{pH}$ and ammonium excretion, although under certain conditions an apparent linear relation between urine $\mathrm{pH}$ and ammonium has been demonstrated (20). In Figure 6, data calculated from previous studies on subjects not salt-depleted $(1,3,4)$ are plotted for comparison with the present experiments to show the relation between the increments in ammonium excretion and the load of extra anion in the urine for the first two days of the loading period. It is seen that in all experiments there is a rough direct proportionality between the initial excretion of ammonium and the excretion of anion, but at all anion loads ammonium excretion in salt-depleted subjects is consistently higher than in subjects on normal diets. In the latter group acidosis was at least as severe as in the present experiments. These facts support the suggestion made elsewhere (18) that ammonium excretion may be determined by the potential discrepancy between the obligatory excretion of anion and the amount of fixed cation which is not reabsorbed by the renal tubules. This mechanism would probably operate through increased tubular exchange of fixed cation for hydrogen or ammonium ions $(20,21)$. According to this hypothesis, sodium depletion enhances ammonium excretion by stimulating renal sodium retention. This hypothesis could also explain the progressive rise of ammonium excretion which occurs during continued administration of ammonium chloride to normal subjects, despite absence of further reduction in extracellular $\mathrm{pH}$ or
TABLE V

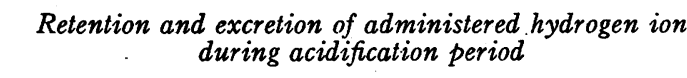

\begin{tabular}{lccccc}
\hline \hline & & \multicolumn{4}{c}{ Hydrogen } \\
\cline { 3 - 6 } Subject & $\begin{array}{c}\text { Treat- } \\
\text { ment } \\
\text { period }\end{array}$ & Given & $\begin{array}{c}\text { Excreted } \\
\left(\mathrm{TA}^{2} \mathrm{NH}_{4}\right)\end{array}$ & $\begin{array}{c}\% \\
\text { excreted }\end{array}$ & $\begin{array}{c}\text { Re- } \\
\text { tained }\end{array}$ \\
\hline & days & $m E q$. & $m E q$. & & $m E q$. \\
H. K. & 2 & 721 & 291 & 40 & 430 \\
J. M. & 3 & 820 & 267 & 33 & 553 \\
A. R. & 3 & 1028 & 344 & 33 & 684 \\
\hline
\end{tabular}

bicarbonate (4). Accumulating deficits of sodium and potassium would tend to increase reabsorption of these ions relative to the anion load and thereby increase the potential cation discrepancy in the urine. In the present experiments, marked increase in the reabsorption of potassium in the immediate post-acidification period would continue the stimulus for excretion of ammonium in excess of the loading anion. This hypothesis does not, of course, exclude the possibility that the influence of increased fixed cation reabsorption on ammonium excretion may be modified by factors related to the renal tubular deaminating reactions, such as the availability of amino acid substrate (22).

It is interesting to compare the relative importance of body buffers and renal acid excretion (ammonium plus titratable acid) in the immediate adjustment to acid loading in these experiments. As shown in Table V, 33 per cent to 40 per cent of the administered hydrogen load appeared in the urine during the two to three-day treatment period. Apparently the body initially disposed of fixed acid invasion largely by sequestration of the administered hydrogen among the total body buffers, while renal excretion played a secondary, though not insignificant, role. Exhaustion of buffer capacity with continued acid loading is prevented by the progressive increase in renal ammonium excretion $(1,4)$.

\section{SUM MARY}

Sodium depletion modified the usual renal response of normal human subjects to acidifying salts in several respects: 1) Ammonium excretion was relatively greater and more prompt ; 2 ) there was no sodium diuresis with urine anion loads less than $125 \mathrm{mEq}$., and sodium constituted only a small, fixed proportion of all cation excreted in 
excess of this amount; 3 ) initial excretion of potassium was increased.

During the period of acid administration most of the hydrogen was distributed among the body buffers with the kidneys playing a secondary role. The largest moiety of the retained hydrogen was buffered in tissue or bone, where it mainly exchanged for potassium. Whole blood buffers received less than a fifth of the retained acid.

The initial renal ammonium response was directly proportional to the rate of excretion of the loading anion and was not related to the degree of extracellular acidosis or to urine $\mathrm{pH}$. In the postacidification period ammonium excretion exceeded the excretion of loading anion by an amount nearly equal to the simultaneous retention of potassium, thus permitting the delivery of hydrogen from intracellular fluid in exchange for potassium.

The data of these studies are consistent with the hypothesis that the stimulus for ammonium excretion was increased tubular reabsorption of fixed cation in the presence of obligatory anion excretion.

\section{ACKNOWLEDGMENTS}

The authors are grateful to Dr. Richard B. Singer for advice on the calculation of whole blood buffer base. Invaluable technical assistance was rendered by Miss Jacquelyn Allen, Miss Helen Connors, Mr. Joseph Greaney, Mrs. Elizabeth Hughes, Mrs. Mary Kimball, and Miss Arlene Roy.

\section{REFERENCES}

1. Gamble, J. L., Blackfan, K. D., and Hamilton, B., A study of the diuretic action of acid producing salts. J. Clin. Invest., 1925, 1, 359.

2. Linder, G. C., The effect of mineral acid on acid-base regulation in health and in nephritis. Quart. J. Med., 1927, 20, 285.

3. Følling, A., On the mechanism of the ammonium chloride acidosis. Acta med. Scandinav., 1929, 71, 221.

4. Sartorius, O. W., Roemmelt, J. C., and Pitts, R. F., The renal regulation of acid-base balance in man. IV. The nature of the renal compensations in ammonium chloride acidosis. J. Clin. Invest., 1949, 28, 423.

5. Van Slyke, D. D., and Cullen, G. E., Studies of acidosis. I. The bicarbonate concentration of the blood plasma; its significance, and its determination as a measure of acidosis. J. Biol. Chem., 1917, 30, 289.
6. Haldane, J. B. S., Experiments on the regulation of the blood's alkalinity. II. J. Physiol., 1921, 55, 265.

7. Kolthoff, I. M., and Sandell, E. B., Textbook of Quantitative Inorganic Analysis. New York, Macmillan, 1948, Chapt. XX.

8. Relman, A. S., and Schwartz, W. B., The effect of DOCA on electrolyte balance in normal man and its relation to sodium chloride intake. Yale J. Biol. \& Med., 1952, 24, 540.

9. Singer, R. B., and Hastings, A. B., An improved clinical method for the estimation of disturbances of the acid-base balance of human blood. Medicine, 1948, 27, 223.

10. Schwartz, W. B., Levine, H. D., and Relman, A. S., The electrocardiogram in potassium depletion: Its relation to the total potassium deficit and the serum concentration. Am. J. Med., 1954, In press.

11. Bergstrom, W. H., Bone as a sodium and potassium reservoir. J. Clin. Invest., 1952, 31, 617.

12. Yeomans, A., and Stueck, G. H., Jr., Clinical-chemical studies of acid-base abnormalities. Am. J. Med., 1952, 13, 183.

13. Cooke, R. E., Segar, W. E., Cheek, D. B., Coville, F. E., and Darrow, D. C., The extrarenal correction of alkalosis associated with potassium deficiency. J. Clin. Invest., 1952, 31, 798.

14. Orloff, J., Kennedy, T. J., Jr., and Berliner, R. W., The effect of potassium in nephrectomized rats with hypokalemic alkalosis. J. Clin. Invest., 1953, 32, 538.

15. Swan, R. C., and Pitts, R. F., Neutralization of infused acid by the nephrectomized dog. Federation Proc., 1953, 12, 140.

16. Grossman, J., Weston, R. E., Hanenson, I. B., Borun, E. R., Guerin, H. A., Ullmann, T. D., Wolfman, M., and Leiter, L., Metabolic studies on ammonium chloride acidosis in patients in congestive heart failure. Federation Proc., 1953, 12, 57.

17. Schwartz, W. B., and Wallace, W. M., Electrolyte equilibrium during mercurial diuresis. J. Clin. Invest., 1951, 30, 1089.

18. Schwartz, W. B., and Relman, A. S., Metabolic and renal studies in chronic potassium depletion resulting from overuse of laxatives. J. Clin. Invest., 1953, 32, 258.

19. Relman, A. S., and Schwartz, W. B., The metabolic effects of Compound $\mathrm{F}$ acetate in man. J. Clin. Invest., 1952, 31, 656.

20. Pitts, R. F., Renal excretion of acid. Federation Proc., 1948, 7, 418.

21. Berliner, R. W., Renal secretion of potassium and hydrogen ions. Federation Proc., 1952, 11, 695.

22. Lotspeich, W. D., and Pitts, R. F., The role of amino acids in the renal tubular secretion of ammonia. J. Biol. Chem., 1947, 168, 611. 